\title{
The role of sibutramine in weight reduction
}

\author{
Pavlik V', Fajfrova $\mathrm{J}^{1}$, Slovacek L ${ }^{2}$, Drahokoupilova $\mathrm{E}^{3}$ \\ University of Defence, Faculty of Military Health Sciences, Department of Military Hygiene, Hradec Kralove, \\ Czech Republic. pavlik@pmfhk.cz
}

\begin{abstract}
Background: The effectiveness of pharmacologic support with sibutramine along with the preservation of dietary and regimen measures is shown in a group of long-term treated patients at the Metabolic Clinic of the University Hospital in Hradec Králové.

Methods: In ambulatory patients, basic anthropometric parameters as body weight, BMI, waist circumference and the total amount of adipose tissue were compared before substitution with $10 \mathrm{mg}$ sibutramine and after a four-month therapy. This group included 94 patients who were administered the same dose of sibutramine for the whole period of time. This group consisted of 37 men and 57 women.

Results: After a four-month therapy with sibutramine there was a mean reduction in weight by $7.9 \pm 3.8 \mathrm{~kg}$ in the monitored group of patients. Their BMI was reduced by $2.3 \pm 1.5 \mathrm{~kg} / \mathrm{height}^{2}$ and the waist circumference by $4.4 \pm 3.8 \mathrm{~cm}$. The decrease in the percentage of the total body lipid was $2.9 \%$.

Conclusion: Despite a surprising decision of the European Drug Agency to suspend the registration of sibutramine in the whole of Europe since January 2010 we can state that in our patients we have proven a positive effect of sibutramine substitution on their weight reduction (Tab. 1, Ref. 19). Full Text in PDF www.elis.sk.

Key words: sibutramine, overweight, obesity, pharmacotherapy of obesity, body mass index.
\end{abstract}

Obesity has become the most frequent metabolic disease as a result of life conditions and lifestyle which have resulted in a positive energetic balance. As far as the number of obese people is concerned Czech Republic is one of the leading EU countries in both, the obesity of men and women (1). The prevalence of obesity and overweight reaches almost $70 \%$ in this country. Obesity represents a severe risk factor which plays an important role in the occurrence of a number of metabolic diseases such as diabetes mellitus, dyslipidemia and atherosclerosis which is manifested as acute myocardial infarction, angina pectoris, ischemic heart disease etc. Obesity has posed a problem to mankind since a very long time. However, at the end of the 20th century it reached the dimension of a global epidemic as a result of constantly increasing energy intake without an adequate increase in energy expenditure (2). Abdominal obesity - a waist circumference of more than $88 \mathrm{~cm}$ in women and of more than $102 \mathrm{~cm}$ in men is considered the most dangerous form of obesity (3).

The treatment of obesity is based on the consistent observance of the diet and exercise regimen $(4,5)$. Without this consistent observance pharmacotherapy should not be initiated. The aim of the modern pharmacotherapy of obesity is to help the patients to reduce their weight and to maintain it on a long-term basis or to treat the metabolic disorders which predispose the individual to develop

${ }^{1}$ University of Defence, Faculty of Military Health Sciences, Department of Military Hygiene, Hradec Kralove, Czech Republic, ${ }^{2}$ University of Defence, Faculty of Military Health Sciences, Department of Internal Medicine, Hradec Kralove, Czech Republic, and ${ }^{3}$ University of Defence, Faculty of Military Health Sciences, Language Training Centre, Hradec Kralove Czech Republic

Address for correspondence: V. Pavlik, MD, PhD, Dept of Military Hygiene, Faculty of Military Health Sciences, University of Defence, Trebesska 1575, CZ-500 01 Hradec Kralove, Czech Republic.

Phone: +420.973253176, Fax: +420.973253013 obesity. In accordance with the recommendations of the Czech Society for Obesity the pharmacotherapy should be initiated in obese patients in the following cases:

- in patients with an initial body mass index (BMI) of more than $30 \mathrm{~kg} / \mathrm{m}^{2}$ if the complex non-pharmacological therapy of obesity failed, that is more than $5 \%$ of weight reduction has not been reached during a three-month period of weight reduction therapy. - in patients with BMI of $27 \mathrm{~kg} / \mathrm{m}^{2}$ or higher in the presence of cardiovascular and metabolic risks (such as arterial hypertension, dyslipidemia, type 2 diabetes mellitus) directly connected with obesity $(6,7)$.

A great advantage of sibutramine is the possibility of its longterm administration due to its enhanced safety profile to reduce adipose tissue and positively influence the risk factors of cardiovascular and metabolic diseases.

\section{Sibutramine as an effective antiobesity agent}

In 2009 sibutramine hydrochloride monohydrate was available in the Czech market as an effective substance in the following preparations: "Meridia, Lindaxa, Sibutramin Teva and Sibutramin Sandoz" in $10 \mathrm{mg}$ and $15 \mathrm{mg}$ capsules. This drug is known in most of the European countries under the trade name Reductil. However, there are also other trade names for this drug such as "Plenty, Reductmine, Reslim, Sibutral or Zytrym". All of these drugs contain an effective substance - sibutramine.

According to the International Union of Pure and Applied Chemistry the chemical name of sibutramine is cyclobutanemethanamine, 1-(4-chlorophenyl)-N,N-dimethyl- $\alpha$-(2-methylprophyl)-, hydrochloride, monohydrate $( \pm)$. Chemical formula: $\mathrm{C}_{17} \mathrm{H}_{26} \mathrm{CIN} \cdot \mathrm{HCI} \cdot \mathrm{H}_{2} \mathrm{O}$.

In 1998 this drug appeared in the American market. One year later it was registered in Europe and in the same year it was also 
registered in the Czech Republic. Sibutramine exerts its pharmacological actions predominantly via its primary $\left(\mathrm{M}_{1}\right)$ and secondary $\left(\mathrm{M}_{2}\right)$ amine metabolites which are inhibitors of noradrenaline, serotonin and dopamine reuptake. In the human brain tissue, metabolites $\left(\mathrm{M}_{1}\right)$ and $\left(\mathrm{M}_{2}\right)$ are a few times more effective in the inhibition of noradrenaline and serotonin reuptake than in the inhibition of dopamine reuptake. A significant inhibition of noradrenaline $(73 \%)$ and serotonin $(54 \%)$ reuptake and an insignificant inhibition of dopamine $(16 \%)$ reuptake were found in the samples of plasma taken from volunteers after administration of sibutramine. Sibutramine and its metabolites are neither substances which release monoamines nor inhibitors of monoamine oxidase. The body weight is reduced either by a decreased food intake which is caused by an early feeling of fullness or the stimulation of thermogenesis by an indirect activation of the sympathetic nervous system through beta receptors of the brown adipose tissue $(8,9)$.

\section{Interactions, adverse reactions, contraindications and dosage}

Severe interactions can be caused by the simultaneous administration of drugs which increase serotonin level in the brain tissue. This phenomenon is called serotonin syndrome and it can rarely occur in connection with the simultaneous administration of selective inhibitors of serotonin reuptake together with some anti-migraine drugs (such as sumatriptan, dihydroergotamine) or in connection with opioids (such as pentazocine, pethidine, fentanyl, dextromethorphan). Sibutramine itself inhibits serotonin reuptake and by this it increases its amount on the nerve synapses. Treatment with inhibitors of monoamine oxidase should not be initiated within two weeks of stopping sibutramine hydrochloride monohydrate therapy. Adverse reactions occur primarily at the beginning of the treatment (during first four weeks). Their severity and frequency diminish over time. These are generally not serious. They do not entail discontinuation of treatment and are reversible. These adverse reactions are: dryness in the mouth, constipation, insomnia, dizziness, nausea, tachycardia, palpitation, vasodilatations, anxiety states, increased perspiration. In some of the clinical studies an increase in the mean value of systolic and diastolic pressure by $2-3 \mathrm{mmHg}$ and an increase in the heart rate by 3-7 heartbeats per minute were observed.

This drug is contraindicated in patients with a history of stroke, ischemic heart disease, especially heart failure and arrhythmias, severe arterial hypertension, closed-angle glaucoma, some mental diseases and eating disorders. Concomitant use of sibutramine hydrochloride monohydrate and monoamine oxidase inhibitors or other centrally-acting preparations for the treatment of psychiatric diseases (antidepressants, antipsychotics) is contraindicated. It is also contraindicated in patients with a history of hyperthyroidism and pheochromocytoma and more severe liver and kidney disorders. As sufficient amount of data is not available this drug is not recommended for pregnant and nursing women. It is also not administered to patients under the age of 18 .

The initial dosage of sibutramine is $10 \mathrm{mg}$ once daily. In patients with an insufficient response to the therapy (weight reduction less than $2 \mathrm{~kg}$ in four weeks) the dosage can be increased to $15 \mathrm{mg}$ once daily. The treatment should be discontinued after three months in patients whose weight loss was less than $5 \%$ of their initial weight. The maximum duration of therapy is recommended to be one year. Minimum effective period of therapy in patients who tolerate the drug well is recommended to be three months. After the therapy with sibutramine is discontinued patients should continue to observe the changed diet and the exercise regimen so that they are able to maintain their reduced weight.

The advantage of sibutramine is the possibility of its long-term administration. Neither the development of heart valve defects nor pulmonary hypertension was proven in patients taking this drug. This drug is not addictive or neurotoxic. Its adverse reactions are associated primarily with the digestive tract and cardiovascular system. Their occurrence is not frequent and they are clinically insignificant. Since 2006 there has been a large reduction in the price of sibutramine in the Czech market. That is why this drug is now available to a broader group of patients who were not able to afford it because of its high price.

\section{Methods}

A group of patients indicated for pharmacotherapy with sibutramine at a dose of $10 \mathrm{mg}$ was selected out of the group of outpatient patients treated at the Metabolic Clinic of the University Hospital in Hradec Králové diagnosed with obesity. Their diet and exercise regimen remained the same.

In all of the obese outpatient patients indicated for the pharmacotherapy, the basic anthropometric parameters such as their weight, BMI, waist circumference and the total amount of adipose tissue before substitution with $10 \mathrm{mg}$ sibutramine and after a fourmonth therapy with the same amount of effective substance were compared in the course of the year 2009.

BMI was calculated in a standard way. BMI $=$ weight $/$ height $^{2}$. The height of patients was measured on a calibrated height gauge and their weight checked by a calibrated scale. The amount of the total body lipid was measured by a multi-frequency analyzer In Body 720 .

This group included 94 patients who were administered the same dose of sibutramine for the whole period of time. This group consisted of 37 men and 57 women. The average age of patients was $47.8 \pm 3.8$. Their age ranged from 21 to 75 years.

\section{Results}

After a four-month therapy with sibutramine at a dose of 10 $\mathrm{mg}$ of effective substance, there was a mean reduction in weight by $7.9 \pm 4.9 \mathrm{~kg}$ in the monitored group of patients. Their BMI was reduced by $2.3 \pm 1.5$ and the waist circumference by $4.4 \pm 3.8 \mathrm{~cm}$. The decrease in the percentage of the total body lipid was $2.9 \%$. The largest weight loss in the monitored group of patients was $26 \mathrm{~kg}$. There was a statistically significant reduction in all of the monitored parameters both in men and women. The initial mean BMI value was $38.3 \pm 5.9$. Out of the total number of 94 patients who underwent a four-month therapy six patients had initial and transient adverse reactions. These adverse reactions were primarily headaches and increased perspiration. None of the patients discontinued pharmacotherapy because of these adverse reactions. None of them had a heart attack or stroke during the course of the therapy. 
Tab. 1. Changes in anthropometric parameters in the whole group of patients after a four month intervention with sibutramine $(n=94)$.

\begin{tabular}{lccc}
\hline & mean & SD & range \\
\hline $\begin{array}{l}\text { Body weight (kg) } \\
\text { baseline }\end{array}$ & 115.1 & 20.2 & $64.0 ; 187.0$ \\
month 4 & $107.2^{*}$ & 20.0 & $58.0 ; 184.0$ \\
change & -7.9 & 4.9 & $-26.0 ; 0.0$ \\
\hline BMI (kg/m2) & & & \\
baseline & 38.3 & 5.9 & $28.0 ; 55.0$ \\
month 4 & $36.0 *$ & 5.8 & $26.0 ; 54.0$ \\
change & -2.3 & 1.5 & $-9.0 ; 0$ \\
\hline waist (cm) & & & \\
baseline & 116.3 & 13.5 & $78.0 ; 145.0$ \\
month 4 & $111.9 *$ & 14.0 & $67.0 ; 141.0$ \\
change & -4.4 & 3.8 & $-21.0 ; 0$ \\
\hline Body fat (\%) & & \\
baseline & 39.8 & 6.0 & $25.6 ; 54.9$ \\
month 4 & $37.0 *$ & 6.7 & $23.1 ; 53.6$ \\
change & -2.9 & 2.1 & $-12.0 ; 0.1$ \\
\hline Body fat (kg) & & & \\
baseline & 46.2 & 12.2 & $18.9 ; 92.2$ \\
month 4 & $40.1 *$ & 3.7 & $-22.0 ; 0$ \\
change & -6.1 & &
\end{tabular}

\section{Discussion}

Constantly increasing number of obese patients necessitates a complex therapy of obesity within the preventive programmes and in everyday medical practice. Only a complex approach to obese patients and the utilization of all available therapeutic methods provides a chance for success. Weight reduction has a positive influence on the quality of life and can significantly decrease health risks of all obese patients $(10,11)$.

The increased number of obese patients also puts pressure on the drug producers to carry out additional research programmes and experimental and clinical studies with the aim to produce new drugs which will be suitable for the therapy of obesity due to their long-term and safe effects. Because of the multifactorial etiopathogenesis of obesity it can be assumed that each anti-obesity agent can have different effectiveness in different patients $(12,13)$.

Sibutramine therapy is not financed by the public health insurance system and hence is not a financial burden for this system (14). Since the end of 2005 the price of sibutramine has decreased significantly caused by expiration of the patent protection of the original preparation and a subsequent registration of a few generics of the original effective substance.

In January 2010 the European Drug Agency based on the outcomes of SCOUT study (Sibutramine Cardiovascular Outcomes) suspended the decision on the registration of sibutramine in the whole of Europe. This study proved increased cardiovascular risks for patients who were taking sibutramine and had a history of ischemic heart disease or stroke (15). All of these high-risk patients were taking sibutramine for a period of six years. The committee of the Czech Society for Obesity has recognized the recommendation of the European Drug Agency to suspend the registration of sibutramine. However, it is persuaded that the administration of sibutramine in accordance with the valid contraindications is beneficial for the patients and that it will be possible to administer this drug again in a short time period $(16,17)$.

\section{Conclusion}

Despite a surprising decision of the European Drug Agency to suspend the registration of sibutramine in the whole of Europe since January 2010 we can state that in our patients we have proven a positive effect of sibutramine substitution on their weight reduction. Some of the patients continued the sibutramine pharmacotherapy for additional months without any adverse reactions and with a positive effect on their weight reduction. An anti-obesity agent containing sibutramine is a modern drug for a long-term, safe and effective weight reduction under the condition that the diet and the exercise regimen are observed and valid contraindications for the drug administration are respected $(18,19)$.

\section{References}

1. Ginter E, Simko V. Adult obesity at the beginning of the 21 st century: epidemiology, pathophysiology and health risk. Bratisl Lek Listy 2008; 109: 224-230.

2. Nisoli E, Carruba MO. A benefit risk assesment of sibutramine in the management of obesity. Drug Saf 2003; 26: 1024-1028.

3. Reaven P. Metabolic syndrome. J Insur Med 2004; 36: 132-142.

4. Mythus-Vliegen EM. Long-term maintenance of weight loss with sibutramine in a GP setting following a specialist guided very-low-calorie diet. Eur J Clin Nutr 2005; 59: 31-35.

5. Waden TA, Berkowitz RI, Womble LG. Randomized trial of lifestyle modification and pharmacotherapy for obesity. N Engl J Med 2005; 353: 2111-2116.

6. Despres JP. Drug treatment for obezity. Br Med J 2001; 322: 1379-1380.

7. Li Z, Maglione M, Tu W. Pharmacologic treatment of obesity. Ann Intern Med 2005; 142: 532-538.

8. Payer J, Hainer V, Ondrejka P. Sibutramine in obesity treatment. Vnitř Lék 2004; 50: 825-829.

9. Luque CA, Rey JA. The discovery and status of sibutramine as an antiobesity drug. Eur J Pharmacol 2002; 440: 119-128.

10. Finer N. Sibutramine in clinical practice. Int J Obes 2001; 25: 12-15.

11. Hainer V. Czech trial of sibutramine in the treatment of obezity. Int J Obes 2001; 25: 107-112.

12. Wettor R, Serra R, Fabris R. Effect of sibutramine on weight management and metabolic control in type 2 diabetes. Diabetes Care 2005; 28: 942-946.

13. Godoy Matos A, CarraroL, Vieira A. Treatment of obese adolescents with sibutramine. J Clin Endocrinol Metab 2005; 90: 1460-1466.

14. Warren E, Brennan A, Akehurst R. Cost-effectiveness of sibutramine in the treatment of obesity. Med Decis making 2004; 24: 9-19.

15. Torp-Pedersen C, Caterson I, Coutinho W et al. Cardiovascular responses to weight management and sibutramine in high-risk subjects: an analysis from the SCOUT trial. Eur heart J 2007; 28 (23): 2915-2923.

16. James WP, Caterson ID, Coutinho W et al. Effect of sibutramine on cardiovascular outcomes in overweight and obese subjects. N Engl J Med 2010; 363 (10): 905-917.

17. Cheng V, Kashyap SR. Weight considerations in pharmacotherapy for type 2 diabetes. J Obes 2011; 2011 pii: 984245.

18. Arterburn D, Crane PK, Veenstra DL. The efficacy and safety of sibutramine for weight loss. Arch Intern Med 2004; 164: 994-999.

19. James WP, Astrup A, Finer N. Effect of sibutramine on weight maintenance after weight loss: a randomised trial. STORM Study Group. Lancet 2000; 356: 2119-2127.

Received July 1, 2010. Accepted September 20, 2012. 